\title{
Empathy Games for Depression Using Virtual Reality: A Literature Review and A Study Design
}

\author{
Yi (Joy) Li \\ Kennesaw State University \\ joy.li@kennesaw.edu
}

\author{
Hao (Irene) Luo \\ Renmin University of China \\ irenehao.luo@gmail.com
}

\author{
Chi Zhang \\ Kennesaw State University \\ chizhang@kennesaw.edu
}

\begin{abstract}
Raising public awareness and accessing information about depression can help the patients receive social support and timely treatment. Studies have shown that serious games benefit education and healthcare. The interactive and immersive environment embedded in serious games can help people learn and apply the concepts. In this paper, we reviewed prior research in designing empathy games for depression using virtual reality (VR). We proposed a study design for a VR game to reflect the feelings and struggling the patients with depression experience through interactive and immersive game scenes. The game intends to cultivate caregivers' empathy and compassion for the patients by enhancing their understanding of depression. By raising social awareness of depression through the immersive game, we hope that this study will encourage discussion and further research in the field.
\end{abstract}

\section{Introduction}

The COVID-19 pandemic starting in March 2020 has changed how people live and interact, consequently had an impact on many people's physical health and mental health $[1,2]$. Fear and anxiety about the pandemic, and isolation at home or in a dedicated quarantine facility could cause overwhelmingly strong emotion, and even depression [3,4]. The symptoms of those who have already been diagnosed with anxiety and depression might be aggravated [1]. Furthermore, the insufficient understanding or knowledge of depression's essence of depression makes families and friends lack empathy for the patients, thus resulting in inadequate support or assistance for the patients. The mechanism of human brains and source of sentiment suggests that depression makes people feel helpless and chronic social defeat [5]. Interpersonal therapy is a feasible and efficient way for families and caregivers to enable efficient remission of depression symptoms and even trigger the possibility of recovery [6].

Game-based digital interventions can be beneficial in improving depression and bonding families and release stress by having entertainment activities together
$[7,8,9]$. The gaming tools, especially virtual reality (VR), have shown that they are capable of facilitating and improving early intervention for mental disorders $[10,11,12]$. In most cases, these emerging technologies are used as supplementary therapy or intervention techniques. They proposed non-intrusive and costeffective ways for mental illness treatments, with the advantages of VR's presence and immersive experience [13]. Prior systematic reviews and meta-analysis papers summarized different types of VR-assisted therapies for mental disorders and their efficiency in recent years [14, $15,16,17]$, including the advantages of VR able to serve as an empathy machine [18]. However, despite the fact that the hardware evolution of head-mounted devices makes VR-based technology portable and affordable over the past decade, not many studies have used VR games for promoting empathy for depression. This motivated us to review the literature about designing empathy games using VR for depression and leverage the review results for game design as the next step of this research.

In this paper, we reviewed previous studies that apply head-mounted virtual reality (not limited to interactive game applications) to promote public awareness and empathy for depression. Based on the findings, we further investigated the VR game design methodologies and recommended the measurements for similar game design studies in the future.

\section{Literature Review}

In this section, we describe the procedure and results from the review of designing empathy games using VR for depression. The PRISMA Statement [19] served as a reference for the review summary.

\subsection{Information Sources and Search Strategies}

Eight databases, Google Scholar, Crossref, PubMed, Science Direct, IEEE, SpringerLink, Wiley, Tylor \& Francis, were searched for the publications between 2010-2020. The time period was determined because most of today's head-mounted VR devices followed the success of Oculus Rift Development Kit 1, which was 
not available until mid-2013 [20]. The objective of this research is to find the studies related to using virtual reality for depression over the past decade. The search terms are: "depress*" in the title words, and "virtual reality" AND "depression" in the keywords. Furthermore, "empathy", "compassion", and "understanding" were used as the keywords to find eligible papers to further distinguish empathy games in the results. The reference lists of the articles were screened for additional studies.

Two researchers (Authors YL and HL) independently identified articles using the same criteria described above and performed cross-check. The other researcher (Author CZ) participated in discussions when there was disagreement on inclusion or exclusion of the papers for the review.

\subsection{Eligibility Criteria}

The review included articles that are:

1) With full text written in English only;

2) Addressing depression or depression-related mental issues;

3) Using methods as either a game or VR (including non-immersive VR videos);

4) Addressing empathy.

\subsection{Study Selection Results}

In March 2020, the eight databases listed above were searched for publications between 2010-2020. The search yielded 427 potentially relevant articles. However, only two studies that are strictly related to using VR for cultivating empathy for depression [21, 22] were found. We had to loosen the inclusion criteria and invited more relevant studies; thus, 169 additional articles were identified and screened. The final ten studies made to the list either have extended the scope to cover the games designed for general empathy training but do not target depression, or the VR applications that are not immersive but only 360-degree videos.

Figure 1 shows the PRISMA flow chart of the search process and the numbers of inclusion and exclusion in each step.

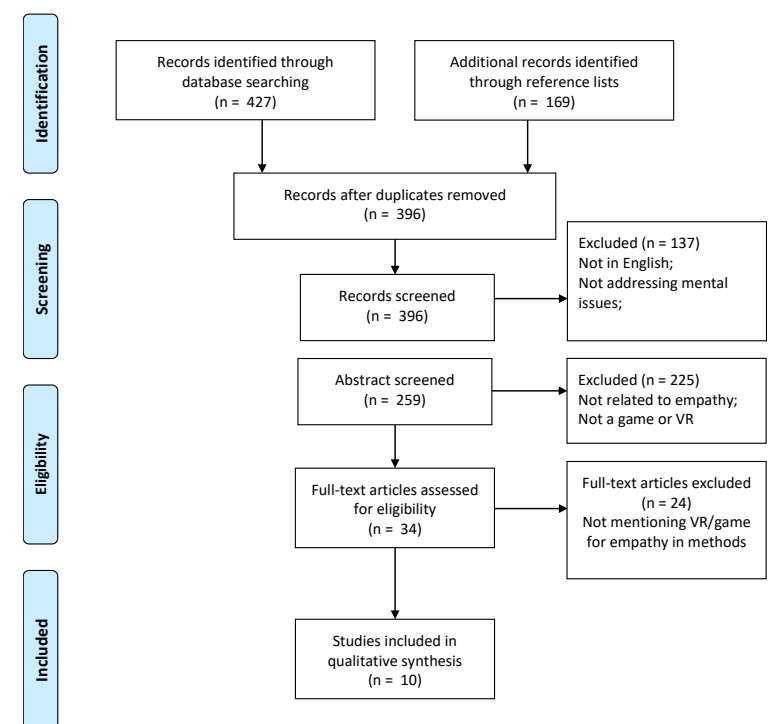

Figure 1. The PRISMA process

\subsection{Study Characteristics}

The Characteristics of Included Studies presented in Table 1 summarizes the information on the individual studies with five entries for each study: Methods, Participants, Interventions, Outcomes and Notes, by following Cochrane Review guidelines [23].

\subsection{Key Findings}

Our results show that researchers have been aware of VR as "an ultimate empathy machine" [24, 25]. Several non-VR video games have been designed to cultivate empathy for mental illness, including depression [26, 27, 28]. While the VR designs and measurements were proposed theoretically for promoting empathy as a general purpose $[29,30]$, these games are not specifically designed for addressing depression. They did not report that actual VR games were implemented to support their theories. Other studies that adopted VR for depression typically were designed for intervention purposes [17, 26], not for empathy, detection, or prevention. The two games using VR designed to increase self-compassion and empathy for depression [21, 22] were VR 360-degree videos and simulations of real-life therapy sessions, respectively, rather than interactive game applications. That is to say, based on our review, no study had designed interactive VR games to promote empathy in depression, nor had they investigated the effectiveness or impact of the games. 
Table 1. Summary of Findings

\begin{tabular}{|c|c|c|c|c|c|}
\hline $\begin{array}{c}\text { Refer } \\
\text { ence }\end{array}$ & Methods & $\begin{array}{c}\text { Particip } \\
\text { ants }\end{array}$ & Experiments & Outcomes & Notes \\
\hline$[24]$ & $\begin{array}{l}\text { A longitudinal ( } 8 \text { weeks) study } \\
\text { short and long-term effects of a } \\
\text { traditional perspective-taking task } \\
\text { and a VR perspective-taking task. }\end{array}$ & $\mathrm{N}=117$ & $\begin{array}{l}\text { Compared three different types of } \\
\text { perspective-taking tasks with } \\
\text { different levels of immersion } \\
\text { (traditional vs desktop computer vs } \\
\text { VR) control group (received fact- } \\
\text { driven information about homeless). }\end{array}$ & $\begin{array}{l}\text { All reported feeling more empathetic } \\
\text { and connected to the homeless. A } \\
\text { significantly higher number of } \\
\text { participants in the VR condition signed } \\
\text { a petition supporting affordable } \\
\text { housing for the homeless. }\end{array}$ & $\begin{array}{l}\text { Higher level of immersion and } \\
\text { interactivity provides higher } \\
\text { level of presence. } \\
\text { Higher physical movement } \\
\text { improves completing } \\
\text { cognitive tasks. }\end{array}$ \\
\hline$[31]$ & $\begin{array}{l}\text { Studied implicit ("arousal") and } \\
\text { explicit ("concern") emotional } \\
\text { empathy in response to positive } \\
\text { and negative emotional stories in } \\
\text { three virtual reality settings in } \\
\text { males and females. }\end{array}$ & $\mathrm{N}=39$ & $\begin{array}{l}\text { Questionnaires were used to assess } \\
\text { trait empathy; EEG was attached to } \\
\text { the chest while playing, and data } \\
\text { were transmitted wirelessly to a } \\
\text { laptop; a motion capture system } \\
\text { tracked participants' movements. }\end{array}$ & $\begin{array}{l}\text { Findings showed that emotional } \\
\text { empathy was context-dependent and } \\
\text { independent of gender. }\end{array}$ & $\begin{array}{l}\text { VR reality empathy paradigm } \\
\text { (VREP) was designed with } 3 \\
\text { environments and } 4 \text { avatars } \\
\text { displaying two emotions } \\
\text { (positive, negative). }\end{array}$ \\
\hline$[32]$ & $\begin{array}{l}\text { Investigated whether the effects of } \\
\text { self-identification with virtual } \\
\text { bodies within immersive VR could } \\
\text { increase self-compassion in } \\
\text { patients with depression. Four } \\
\text { different measurements were used } \\
\text { as questionnaires. }\end{array}$ & $\begin{array}{l}\mathrm{N}=15 \\
10 \\
\text { female, } 5 \\
\text { male, } \\
\text { age 23- } \\
61 .\end{array}$ & $\begin{array}{l}\text { Participants completed assessments } \\
\text { in the first session; In the second } \\
\text { session, 8-minute VR scenarios } \\
\text { were used to let participants practice } \\
\text { delivering compassion in a virtual } \\
\text { body and then receiving it from } \\
\text { themselves in another virtual body. }\end{array}$ & $\begin{array}{l}\text { Significant reductions in depression } \\
\text { severity and self-criticism, as well as } \\
\text { increases in self-compassion; and } \\
\text { repeating sessions deepened the } \\
\text { patients' experience. Immersive virtual } \\
\text { reality is an intervention this clinical } \\
\text { group can potentially benefit from. }\end{array}$ & $\begin{array}{l}\text { The VR has an accurate 3D } \\
\text { model of an actual room. A } \\
\text { virtual mirror was added to let } \\
\text { the participants see } \\
\text { themselves. The embodied } \\
\text { virtual characters include an } \\
\text { adult and a child. }\end{array}$ \\
\hline [33] & $\begin{array}{l}\text { The design was between-groups } \\
\text { comparing a first-person } \\
\text { perspective (1PP) and a third- } \\
\text { person perspective (3PP) } \\
\text { condition. Six different } \\
\text { measurements were used as } \\
\text { questionnaires. }\end{array}$ & $\begin{array}{l}\mathrm{N}=24 \\
\text { females }\end{array}$ & $\begin{array}{l}\text { In the first phase, highly self-critical } \\
\text { participants showed compassion } \\
\text { with a crying child avatar while } \\
\text { embodied in an adult avatar. In the } \\
\text { second phase, participants embodied } \\
\text { the child avatar and reexperience } \\
\text { their compassionate response from } \\
\text { this embodied perspective. }\end{array}$ & $\begin{array}{l}\text { Rehearsing the delivery and receipt of } \\
\text { compassionate behavior leads to a } \\
\text { reduction in self-criticism; exploiting } \\
\text { the IVR technique of embodiment in } \\
\text { the recipient has the additional effect of } \\
\text { positively increasing self-compassion. } \\
\text { The study shows that VR can be used } \\
\text { to train positive emotions. }\end{array}$ & $\begin{array}{l}\text { The VR has an accurate 3D } \\
\text { model of an actual room. A } \\
\text { virtual mirror was added to let } \\
\text { the participants see } \\
\text { themselves. The embodied } \\
\text { virtual characters include an } \\
\text { adult and a child. }\end{array}$ \\
\hline [29] & $\begin{array}{l}\text { This is a theoretical analysis of } \\
\text { different mechanisms of empathic } \\
\text { practices for empathic training in } \\
\text { VR. Training methods for empathy } \\
\text { include role-playing, mindfulness } \\
\text { training, implementation of } \\
\text { egalitarian goals. }\end{array}$ & $\mathrm{N} / \mathrm{A}$ & $\begin{array}{l}\text { Empathy-related training practices } \\
\text { are analyzed and categorized. The } \\
\text { authors also identify different } \\
\text { variables used by pioneer studies in } \\
\text { VR to promote empathy-related } \\
\text { responses. }\end{array}$ & $\begin{array}{l}\text { Existent strategies for learning } \\
\text { empathy-related abilities: } \\
\text { * social and emotional learning (SEL); } \\
\text { * constructivism; } \\
\text { * safe environment for positive } \\
\text { intergroup interaction. }\end{array}$ & $\begin{array}{l}\text { Generic empathy training } \\
\text { using VR theoretically, not } \\
\text { specifically for depression. } \\
\text { Provided solid reference for } \\
\text { methods can be used. }\end{array}$ \\
\hline [28] & $\begin{array}{l}\text { A video game was designed to } \\
\text { promote empathy for people with } \\
\text { depression, and it applies a } \\
\text { personal story with a series of } \\
\text { events. Empathy was assessed } \\
\text { after the game was played. }\end{array}$ & $\begin{array}{l}\mathrm{N}=20 ; 4 \\
\text { were } \\
\text { excluded } \\
\text { from the } \\
\text { study. }\end{array}$ & $\begin{array}{l}\text { A pre-test with six different } \\
\text { questions regarding depression and } \\
\text { general mode was given before the } \\
\text { game. The game is of } 10 \text { to } 20 \\
\text { minutes of gameplay. After the } \\
\text { game, a post-test was given with } \\
\text { four questions. }\end{array}$ & $\begin{array}{l}\text { The results of the study showed a } \\
\text { change in mood from pretest and } \\
\text { posttest, pointing toward empathy } \\
\text { being transferred to the player. }\end{array}$ & $\begin{array}{l}\text { Five text/video games } \\
\text { designed in regard to } \\
\text { depression were reviewed and } \\
\text { used as a reference for } \\
\text { designing Obliti. This is not a } \\
\text { VR game. }\end{array}$ \\
\hline
\end{tabular}


Table 1. Continued

\begin{tabular}{|c|c|c|c|c|c|}
\hline $\begin{array}{c}\text { Refer } \\
\text { ence }\end{array}$ & Methods & $\begin{array}{c}\text { Partici } \\
\text { pants }\end{array}$ & Experiments & Outcomes & Notes \\
\hline$[22]$ & $\begin{array}{l}\text { The study explored the emotional } \\
\text { reactions of participants changed } \\
\text { according to the confederate's } \\
\text { status signals and ethnic groups. } \\
\text { Participants' alertness, calmness, } \\
\text { and engagement were monitored } \\
\text { during the VR video sessions. } \\
\text { Participants' distress and empathy } \\
\text { when exposed to helping } \\
\text { interactions were self-assessed. }\end{array}$ & $\begin{array}{l}\mathrm{N}=40 \\
19 \\
\text { women } \\
\text { and } 21 \\
\text { men, } \\
\text { age } 23- \\
76 .\end{array}$ & $\begin{array}{l}\text { A set of virtual scenarios was } \\
\text { created in which the confederate's } \\
\text { ethnicity (white vs. black) and social } \\
\text { appearance (businessman vs. beggar, } \\
\text { with casual dress as a control } \\
\text { condition) were crossed. EEG was } \\
\text { used during the sessions, and self- } \\
\text { assessment was used after each } \\
\text { session. }\end{array}$ & $\begin{array}{l}\text { White participants showed higher levels } \\
\text { of alertness when exposed to helping } \\
\text { interactions involving a white beggar or } \\
\text { a black businessman, and their } \\
\text { emotional calmness and engagement } \\
\text { were higher when interacting with a } \\
\text { black beggar or a white businessman. } \\
\text { The results for self-assessed distress and } \\
\text { empathy followed the same tendency. }\end{array}$ & $\begin{array}{l}\text { Full degrees of immersive } \\
\text { videos were used instead of } \\
\text { real VR game scenes. }\end{array}$ \\
\hline$[21]$ & $\begin{array}{l}\text { The study analyzed the effects of a } \\
\text { self-compassion meditation } \\
\text { supported by an embodied VR } \\
\text { system (TMTBA-VR) compared to } \\
\text { usual practice (only audio). } \\
\text { Ten commonly used questionnaires } \\
\text { were used for assessment. }\end{array}$ & $\mathrm{N}=16$ & $\begin{array}{l}\text { Participants were randomly assigned } \\
\text { into two groups (usual meditation vs } \\
\text { VR assisted meditation). Pre- and } \\
\text { Post- assessment were filled before } \\
\text { and after the meditation. The } \\
\text { mediation of two groups used the } \\
\text { same audio and focused in a self- } \\
\text { compassionate state. Participants } \\
\text { practiced the mediation for the } \\
\text { following } 2 \text { weeks, then they } \\
\text { completed a follow-up assessment. }\end{array}$ & $\begin{array}{l}\text { Both groups significantly increased } \\
\text { positive qualities toward self/others, } \\
\text { decreased negative qualities toward self, } \\
\text { and increased awareness and attention to } \\
\text { mental events and bodily sensations. } \\
\text { After } 2 \text { weeks, both groups increased in } \\
\text { specific types of self-care behaviors. } \\
\text { The frequency of clinical self-care } \\
\text { behaviors being significantly higher in } \\
\text { VR group. }\end{array}$ & $\begin{array}{l}\text { Compassion-based } \\
\text { interventions (CBIs) have } \\
\text { been shown to be effective for } \\
\text { increasing empathy and } \\
\text { compassion, reducing stress, } \\
\text { anxiety, and depression. VR is } \\
\text { believed to be useful to help } \\
\text { with the limitation of imagery } \\
\text { abilities. The VR used here is } \\
\text { a real-time camera for training } \\
\text { compassion on the virtual self. }\end{array}$ \\
\hline [34] & $\begin{array}{l}\text { A qualitative interpretive method } \\
\text { was used to assess human } \\
\text { mediation to teach social and } \\
\text { emotional learning skills, based on } \\
\text { the premise that cognitive and } \\
\text { social-emotional development } \\
\text { occurs synergistically and } \\
\text { mediated by speech and interaction } \\
\text { with the environment. }\end{array}$ & N/A & $\begin{array}{l}\text { Trace the links between empathy } \\
\text { development and social and } \\
\text { emotional learning when using real } \\
\text { versus virtual environments. }\end{array}$ & $\begin{array}{l}\text { The interaction (human-to-human, } \\
\text { human-to-avatar, avatar-to-avatar) in the } \\
\text { virtual world is most important, not } \\
\text { the participation in a virtual realm itself. } \\
\text { Effective virtual environments require } \\
\text { an even more careful balance of } \\
\text { elements (support and scaffolding vs } \\
\text { opportunities for independence) than } \\
\text { traditional play settings. }\end{array}$ & $\begin{array}{l}\text { This paper reviews previous } \\
\text { research works (both } \\
\text { empirical and theoretical) that } \\
\text { bring to light the connection } \\
\text { between socio-emotional } \\
\text { development, specifically } \\
\text { empathy development, and } \\
\text { virtual environments. }\end{array}$ \\
\hline [30] & $\begin{array}{l}\text { The study reviewed literature and } \\
\text { proposed a hypothesis of research } \\
\text { that, by using VR in subjects with a } \\
\text { diagnosis of Personality Disorder } \\
\text { to increase empathy. Meanwhile } \\
\text { the possibility of using a mobile } \\
\text { app is linked to multiple VR } \\
\text { viewers for psychotherapy. }\end{array}$ & N/A & $\begin{array}{l}\text { Existing literature about the } \\
\text { construct of empathy were reviewed. } \\
\text { The author discussed a theoretical } \\
\text { assumption of including VR in both } \\
\text { empowering empathy and clinical } \\
\text { psychotherapy. The limits for VR } \\
\text { are also discussed. }\end{array}$ & $\begin{array}{l}\text { This work presented the necessity to } \\
\text { find a middle ground where } \\
\text { psychotherapy and phenomenological } \\
\text { research can join new technologies in } \\
\text { order to promote scientific progress, } \\
\text { implementing new therapeutic } \\
\text { techniques. }\end{array}$ & $\begin{array}{l}\text { The study stated that VR is a } \\
\text { new form of measurement for } \\
\text { increasing empathy, } \\
\text { specifically for depression. } \\
\text { It is merely a discussion of } \\
\text { possibility, while no concrete } \\
\text { methods or study design were } \\
\text { proposed. }\end{array}$ \\
\hline
\end{tabular}


As discussed in a recent article studying empathy [35], the definition of empathy nowadays adopts a tripartite classification: cognitive empathy (mental perspective taking), affective empathy (the vicarious sharing of emotion), and compassionate empathy (the feel and the willingness to help other people to deal with his situation and his emotions). As shown in Table 2, among the studies designed to increase empathy, we found three of them explicitly addressed cognitive empathy $[29,30,36]$, and four addressed affective/emotional empathy [21, 22, 29, 31]. The rest of the three studies either only mentioned these dimensions without designing particularly to one of them, or simply treated empathy as a singular term without differentiating its types. For future studies, we recommend that researchers clarify which type of empathy they target to promote, and how they test the efficacy of adopting VR games. More in-depth studies are also recommended to determine which game elements are beneficial to which type of empathy. In addition, since "compassionate empathy is seen as the most socially desirable [35]", more research will be needed to study how to cultivate compassionate empathy effectively.

\section{Table 2. Different types of empathy and studies that target them}

\begin{tabular}{|l|l|l|l|}
\hline $\begin{array}{l}\text { Empathy } \\
\text { Types }\end{array}$ & $\begin{array}{l}\text { Cognitive } \\
\text { Empathy }\end{array}$ & $\begin{array}{l}\text { Affective } \\
\text { Empathy }\end{array}$ & $\begin{array}{l}\text { Compassionate } \\
\text { Empathy }\end{array}$ \\
\hline Studies & {$[29, \quad 30$,} & $\begin{array}{l}{[21, \quad 22,} \\
29,31]\end{array}$ & N/A \\
& $36]$ & & \\
\hline
\end{tabular}

\section{Discussion}

Our review indicates that future studies on VR as an empathy machine have the potential to address the importance of empathy for depressive people and enhance the awareness of being empathetic. Since there is a considerably large open space for this research topic, a number of directions could be explored in future studies.

Psychological studies found that social support is one of the key factors in helping patients recover from depression, in addition to counseling sessions and medications [37, 38, 39]. Moreover, patients with depression need high-quality company. It is vital for patients to have social support and to learn to express their negative emotions. They also need to identify and track the cognitive distortions in their thinking, before the distortions start working and change them. Most current serious games for public awareness of depression [27, 40, 41] focus on one-sided empathy by letting caregivers experience how patients feel. Yet none of them attempted to train synaesthesia or mutual understanding between patients and caregivers to enhance social support, besides helping patients to recognize their needs, encouraging them to seek help and liberating them from further possible negative emotions.

Furthermore, due to the pandemic of COVID-19, more people are at risk of anxiety or depression and may respond more strongly to the stress $[2,42]$. The change in living conditions, and possibly reduced income [43] is also a factor. To better understand their needs and to better help them, playing VR games would enable people to experience the feeling of patients with depression vividly. It helps raise public awareness about mental illness and help people recognize the symptoms of anxiety and depression. As a result, patients can be encouraged to take prompt action to seek professional help.

Moreover, adopting VR games for learning empathy is widely recognized in medical education $[29,44,45,46]$. The immersion and embodiment of VR applications have been proven to be able to help medical students visualize and understand patients' feelings in order to better help them. Pilot studies in medical education have reported in cultivating empathy for older people [47], as well as in nausea and vomiting management [48], among others. Yet no studies have been made explicitly for training empathy for depression.

As we understand more about what the VR games can help, it is worth investigating the effectiveness of designing VR games that aim to cultivate empathy in different social roles (family, friends, medical students, public, etc.). Figure 2 shows how it will benefit both the prevention and intervention methods of depression. The solid arrows indicate the direct impact, which can be measured from the games with in-game performance data analysis, in combination with traditional pre- and post- questionnaires. The dashed arrows indicate indirect impact, yielding exciting and prosocial outcomes, but they may be challenging to measure. For depression prevention, as a suggestion prosocial questionnaires could be used for participants to predict what they will do if they themselves or others show the symptoms. Cohort studies could also be a choice to track the mental health of the participants in comparison to the control group to testify the effectiveness on prevention. Similarly, for the impact on intervention, prosocial questionnaires could be used on medical students or healthcare providers who participate. Cohort studies could be considered in a pair-wise manner to track healthcare providers and their patients, in order to decide whether promoting empathy in medical students or healthcare providers will benefit the actual treatment for patients. 


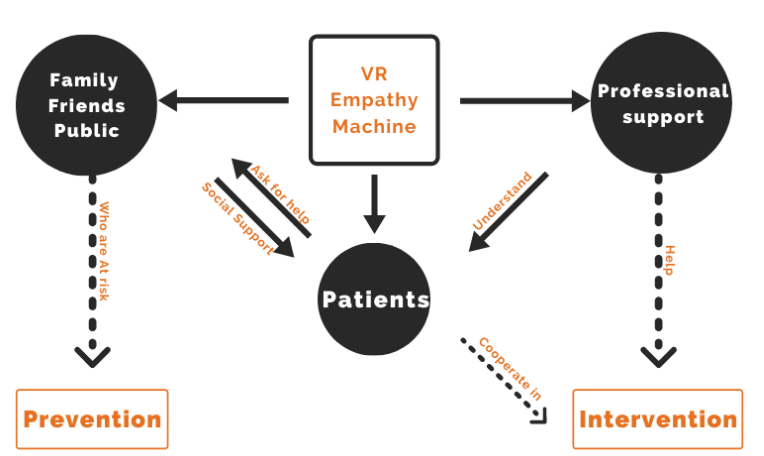

Figure 2. VR as an empathy machine in future studies

\section{Proposed Study Design}

The key findings of the related work show the lack of designing VR interactive games for improving empathy for depression. To fill the gap, we propose a design by raising mutual understanding and empathy between patients and social support providers (family members, friends, or other people), which may be able to encourage patients to receive treatment more willingly and more effectively. The measurements to assess the effectiveness of the games with these objectives are introduced and discussed in the next subsections. As very few studies have done similar work before, we designed a study plan with a VR game application in the hope of proposing a framework for developing future VR games for the same purpose as promoting empathy for depression in different social roles described in Figure 2 and how to measure their efficacy. We plan to test the hypothesis on the basis of the established measurements in empathy training [49, $59,60]$.

\subsection{Empathy Game Design using VR}

We name our VR empathy game as "Schwer", a German word, meaning "heavy" or "distress" in English. The targeted audience includes (1) the patients diagnosed with depression; (2) caregivers such as family and friends.

The proposed game intends to establish cognitive empathy for depressive disorders in both patients and caregivers. The main goal of this game is not to provide direct intervention for patients with depression. By facilitating the communication and connection between caregivers and patients, the game is seeking a better social environment for patients to survive, initiate linkage and educate others who care to engage with them appropriately.

The game is designed and still in progress with the help of a clinical counselor and two patients with major depression along the course of development and implementation. Feedback and comments are provided in regular remote meetings and demo presentations. All the objectives proposed can be quantitatively measured.

4.1.1. System architecture. The game is VR-based, fully immersive, and with narrative and interaction designs, as opposed to a simple recorded VR 360 video or a simulation of an intervention session. This is to fully utilize the presence and immersion experience of VR devices and motion feedback for promoting empathy. Unity game engine is used to develop the game, and the targeted platforms include two major popular VR headsets: Oculus and HTC Vive. Patients with depression will be collaborated to design some artworks, environments, storylines, and level maps/events, to provide an opportunity for them to metaphorically express their feelings. Potential eyetracking and reaction time monitoring may be adopted in tracking the progress, as a study reported the correlation between eyes/head movement and depression intensity [50]. Music and sound effect will be rendered to assist the empathy and intervention purposes.

4.1.2. Game mechanism. The game is an adventure and construction game with a first-person view. The suffering of distress from patients with depression is represented by distorted images, narrow and dim views, slow movement, color-coded backgrounds, variable sound effects, and challenging events.

4.1.3. Empathy and intervention features. Colors, rewards, and positive reinforcement will be used to help build connections between patients and caregivers. Caregivers (another role in the game) will learn from the examples for appropriate emotional support, while patients will go through cognitive restructuring, a process of letting patients identify their cognitive distortions and alter thoughts and behaviors.

Depression often causes cognitive impairment and emotional impairment, which has a significant impact on the patient's functioning and quality of life [51]. As the third objective specifies, patients often lack the willingness and ability to ask for help even when they are desperate. Inspired by the concept used in cognitive behavioral therapy (CBT) $[52,53,54]$ and mindfulness-based intervention $[55,56,57,58]$, we designed a game flow for training cognitive behavior with an upward spiral process, which is depicted by Figure 3:

- In the beginning, the subject lacks the willingness and ability to ask for help; 
- The subject will learn how to express negative feelings and ask for help from an NPC to survive in the game world;

- $\quad$ The subject gains the feeling of control and efficacy from the game feedback, e.g., getting a hint or shortcut from NPC to solve the problem;

- The subject learns that asking for help is an option in reality that she should not be ashamed of, and that the behavior benefits both sides;

- Help and feedback from caregivers in the realworld will reduce the subject's feeling of incapability and self-criticism;

- The cognitive behavior has been reshaped, and the subject gets into another round of enhancement or reshape.

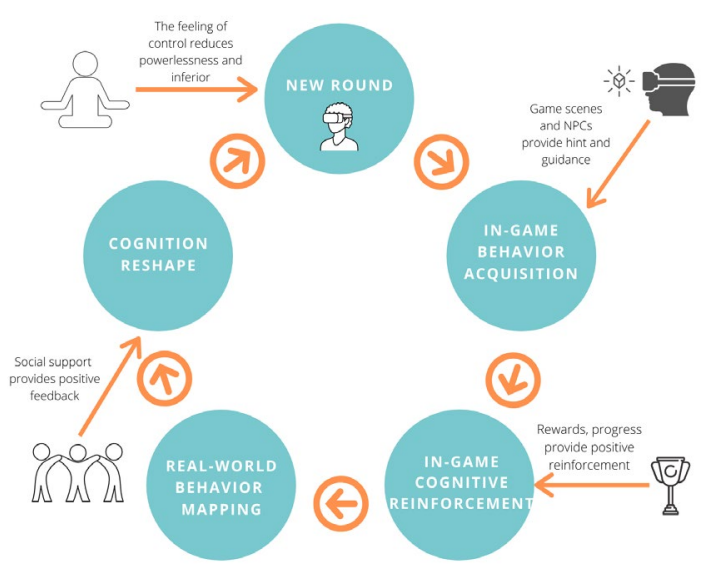

Figure 3. The upward spiral of cognitive behavior

\subsection{Experimental Design}

Three groups of participants will be recruited to join the study. They consist of a group of patients diagnosed with moderate or major depression, a group of friends or family of the patient group, and a group without any mental conditions as the control group or "the public". In each session, each subject will fill out the pre- and post- questionnaires described in the next subsection. The results of each group will be compared and analyzed within and across groups. The patientscontrol and patients-caregivers differences will be carefully assessed for the effectiveness of promoting empathy and synesthesia or lack thereof.

The design hinges on the hypothesis that all the groups will increase in cognitive empathy and mutual understanding between the patient group and the friends/family group will be increased.

\subsection{Measures}

Quantitative measures will be used in assessing the objectives of the game. Informed by the literature of empathy games, we propose to use the following measures for the current study. The questionnaires will be tailored toward empathy for depression instead of generic empathy for other people's feelings or sufferings.

1) Virtual reality experience measures. To analyze the efficacy of using VR as a tool for empathy elicitation, a questionnaire derived from [32] includes a few questions about the presence and immersion experience after the session, as well as real-time behavior recording. In addition, eyetracking and reaction time can be integrated to quantitatively analyze the emotional reactivity to virtual events.

2) The pre- and post- empathy scale for depression, derived from the Interpersonal Reactivity Index (IRI) [49]. The IRI is used to test four factors of the empathy ability of individuals towards others, including measures for cognitive empathy and emotional empathy.

3) Forms of Self-Criticizing/Attacking \& SelfReassuring Scale (FSCRS) [59]. The FSCRS form evaluates the feeling of worthless, useless, or inferior. The improvement of this measurement will reflect the cognitive behavior that we aim to reshape in the $3^{\text {rd }}$ objective.

4) Patient-caregiver empathy questionnaire, which will be tailored from the self-other four immeasurable scales (SOFI) [60] and customized for the specific purpose. The SOFI scale assesses the positive and negative attitudes towards self and others. It is reasonable to use SOFI to identify the improvement in mutual understanding and communication between patients and caregivers.

\section{Conclusion and Future Work}

Our literature review reveals that most of the VR games developed for depression intend to introduce intervention methodologies for promoting empathy in depression. However, as of this review was conducted, none of the existing attempts in using VR 360 videos or simulations has used immersive and interactive VR game scenes with narratives. Furthermore, none of the current studies addressed the direct social support that patients can have and focus on promoting empathy towards both sides. We hope to contribute to the field because not only should caregivers pay attention and learn to provide support to the patients, but the patients should also be aware of the help they may get, 
meanwhile cognitively change their behavior and give caregivers feedback to build mutual and healthy connection.

Most importantly, we pointed out a few directions for future studies that aim to contribute to this topic. With the possibility of direct and indirect impacts on different social roles in society, VR as an empathy machine is believed to be beneficial to both prevention and intervention methods for depression.

\section{References}

[1] Neighmond, P., "Coronavirus Crisis May Worsen Symptoms In Children With Anxiety, Depression”, NPR.org, 2020.

https://www.npr.org/2020/05/21/859991352/coronaviruscrisis-may-worsen-symptoms-in-children-with-anxietydepression

[2] Wan, W., "The coronavirus pandemic is pushing America into a mental health crisis", Washington Post, 2020.

https://www.washingtonpost.com/health/2020/05/04/mental -health-coronavirus/

[3] Brooks, S.K., R.K. Webster, L.E. Smith, L. Woodland, S.Wessely, N. Greeberg, and G.J. Rubin, "The psychological impact of quarantine and how to reduce it: rapid review of the evidence", Lancet (London, England) 395(10227), 2020, pp. 912-920.

[4] Shigemura, J., R.J. Ursano, J.C. Morganstein, M. Kurosawa, and D.M. Benedek, "Public responses to the novel 2019 coronavirus (2019-nCoV) in Japan: Mental health consequences and target populations", Psychiatry and Clinical Neurosciences 74(4), 2020, pp. 281-282.

[5] Venzala, E., A.L. García-García, N. Elizalde, P. Delagrange, and R.M. Tordera, "Chronic social defeat stress model: behavioral features, antidepressant action, and interaction with biological risk factors",

Psychopharmacology 224(2), 2012, pp. 313-325.

[6] Brody, A.L., S. Saxena, P. Stoessel, et al., "Regional Brain Metabolic Changes in Patients With Major Depression Treated With Either Paroxetine or Interpersonal Therapy: Preliminary Findings", Archives of General Psychiatry 58(7), 2001, pp. 631-640.

[7] Davies, E.B., R. Morriss, and C. Glazebrook,

"Computer-delivered and web-based interventions to improve depression, anxiety, and psychological well-being of university students: a systematic review and metaanalysis", Journal of Medical Internet Research 16(5), 2014, pp. e130.

[8] Li, J., Y.-L. Theng, and S. Foo, “Game-Based Digital Interventions for Depression Therapy: A Systematic Review and Meta-Analysis", Cyberpsychology, Behavior and Social Networking 17(8), 2014, pp. 519-527.

[9] Lobel, A., R.C.M.E. Engels, L.L. Stone, W.J. Burk, and I. Granic, "Video Gaming and Children's Psychosocial Wellbeing: A Longitudinal Study", Journal of Youth and Adolescence 46(4), 2017, pp. 884-897.

[10] Maples-Keller, J.L., B.E. Bunnell, S.-J. Kim, and B.O. Rothbaum, "The use of virtual reality technology in the treatment of anxiety and other psychiatric disorders", Harvard review of psychiatry 25(3), 2017, pp. 103-113. [11] Ose, S.O., H. Færevik, J. Kaasbøll, et al., "Exploring the Potential for Use of Virtual Reality Technology in the Treatment of Severe Mental Illness Among Adults in MidNorway: Collaborative Research Between Clinicians and Researchers", JMIR Formative Research 3(2), 2019.

[12] Park, M.J., D.J. Kim, U. Lee, E.J. Na, and H.J. Jeon, "A Literature Overview of Virtual Reality (VR) in Treatment of Psychiatric Disorders: Recent Advances and Limitations", Frontiers in Psychiatry 10, 2019.

[13] Li, Y., A.S. Elmaghraby, A.S. El-Baz, M.F. Casanova, and E.M. Sokhadze, "Virtual Reality as a Tool for Investigation of Autonomic Reactivity in Autism", Applied Psychophysiology and Biofeedback, SPRINGER/PLENUM PUBLISHERS 233 SPRING ST, NEW YORK, NY 10013 USA (2016), 444-444.

[14] Juan, M.-M., and L.-A. Magí, "Using Agents in Mental Health: A System to Support the Remote Treatment of Major Depression", Frontiers in Artificial Intelligence and Applications, 2010, pp. 101-110.

[15] Newman, M.G., L.E. Szkodny, S.J. Llera, and A. Przeworski, "A review of technology-assisted self-help and minimal contact therapies for anxiety and depression: Is human contact necessary for therapeutic efficacy?", Clinical Psychology Review 31(1), 2011, pp. 89-103. [16] Preschl, B., B. Wagner, S. Forstmeier, and A. Maercker, "E-health interventions for depression, anxiety disorders, dementia, and other disorders in old age: A review", Journal of CyberTherapy and Rehabilitation 4, 2011, pp. 371-385.

[17] Zeng, N., Z. Pope, J.E. Lee, and Z. Gao, "Virtual Reality Exercise for Anxiety and Depression: A Preliminary Review of Current Research in an Emerging Field”, Journal of Clinical Medicine 7(3), 2018, pp. 42. [18] Hassan, R., "Digitality, Virtual Reality and the 'Empathy Machine'”, Digital Journalism 8(2), 2020, pp. 195-212.

[19] Liberati, A., D.G. Altman, J. Tetzlaff, et al., "The PRISMA Statement for Reporting Systematic Reviews and Meta-Analyses of Studies That Evaluate Health Care Interventions: Explanation and Elaboration", PLOS Medicine 6(7), 2009, pp. e1000100.

[20] Dybsky, D., "The History of Virtual Reality: Ultimate Guide. Part 2 | TESLASUIT blog”, TESLASUIT, 2017. https://teslasuit.io/blog/history-virtual-reality-ultimateguide-part-2/

[21] Cebolla, A., R. Herrero, S. Ventura, et al., "Putting Oneself in the Body of Others: A Pilot Study on the Efficacy of an Embodied Virtual Reality System to Generate Self-Compassion", Frontiers in Psychology 10, 2019.

[22] D'Errico, F., G. Leone, M. Schmid, and C. D'Anna, "Prosocial Virtual Reality, Empathy, and EEG Measures: A Pilot Study Aimed at Monitoring Emotional Processes in Intergroup Helping Behaviors", Applied Sciences 10, 2020, pp. 1196.

[23] Higgins, J., J. Thomas, J. Chandler, et al., Cochrane Handbook for Systematic Reviews of Interventions. 2nd Edition, Chichester (UK): John Wiley \& Sons, 2019. 
[24] Herrera, F., J. Bailenson, E. Weisz, E. Ogle, and J. Zaki, "Building long-term empathy: A large-scale comparison of traditional and virtual reality perspectivetaking", PLOS ONE 13, 2018, pp. e0204494.

[25] Milk, C., "How virtual reality can create the ultimate empathy machine", 2015.

https://www.ted.com/talks/chris_milk_how_virtual_reality_ can_create_the_ultimate_empathy_machine

[26] Granic, I., "DEEP-VR: A stunning virtual reality game for anxiety and depression (Pt. 5)", Its Your TURN, 2017.

[27] Jin, W., D. Gromala, and T. Xin, "Serious game for serious disease: Diminishing stigma of depression via game experience", 2015 IEEE Games Entertainment Media Conference (GEM), IEEE (2015), 1-2.

[28] Stevens, M., "Obliti-Empathy game regarding depression", 2018. https://digitalcommons.wpi.edu/etdtheses/353/

[29] Bertrand, P., J. Guegan, L. Robieux, C.A. McCall, and F. Zenasni, "Learning Empathy Through Virtual Reality: Multiple Strategies for Training Empathy-Related Abilities Using Body Ownership Illusions in Embodied Virtual Reality", Frontiers in Robotics and AI 5, 2018, pp. 26.

[30] Nascivera, N., Y. Alfano, T. Annunziata, et al., Virtual Empathy The added value of Virtual Reality in Psychotherapy, 2020.

[31] Kuypers, K., "Context-dependent emotional empathy in virtual reality (Empathy in virtual reality)", Advances in Social Sciences Research Journal 5, 2018.

[32] Falconer, C.J., A. Rovira, J.A. King, et al., "Embodying self-compassion within virtual reality and its effects on patients with depression", BJPsych Open 2(1), 2016, pp. 74-80.

[33] Falconer, C.J., M. Slater, A. Rovira, et al., "Embodying Compassion: A Virtual Reality Paradigm for Overcoming Excessive Self-Criticism", PLOS ONE 9(11), 2014, pp. e111933.

[34] Walker Gabriela, and Venker Weidenbenner Jeni, "Social and Emotional Learning in the age of virtual play: technology, empathy, and learning", Journal of Research in Innovative Teaching \& Learning 12(2), 2019, pp. 116-132. [35] Powell, P.A., and J. Roberts, "Situational determinants of cognitive, affective, and compassionate empathy in naturalistic digital interactions", Computers in Human Behavior 68, 2017, pp. 137-148.

[36] Małgorzata, P.W., and R. Joanna, “A SERIOUS GAME RAISING AWARENESS AND EXPERIENCE OF DEPRESSION", INTED2015 Proceedings, 2015, 14371444.

[37] Brown, G.W., B. Andrews, T. Harris, Z. Adler, and L. Bridge, "Social support, self-esteem and depression", Psychological Medicine 16(4), 1986, pp. 813-831.

[38] Dupuis, E.C., and M.A. Ramsey, "The relation of social support to depression in massively multiplayer online role - playing games" , Journal of applied social psychology, 2011.

[39] Lin, N., A. Dean, and W.M. Ensel, Social Support, Life Events, and Depression, Academic Press, 2013.

[40] "Gone Home: A Story Exploration Video Game", https://gonehome.game/

[41] "RiME: Puzzles Guide | Chapter 1 Walkthrough | Walkthroughs | The Escapist", https://v1.escapistmagazine.com/articles/view/videogames/walkthroughs/17758-RiME-Puzzles-Guide-Chapter1-Walkthrough

[42] Salari, N., A. Hosseinian-Far, R. Jalali, et al., "Prevalence of stress, anxiety, depression among the general population during the COVID-19 pandemic: a systematic review and meta-analysis", Globalization and Health 16(1), 2020, pp. 57.

[43] Wilson, J.M., J. Lee, H.N. Fitzgerald, B. Oosterhoff, B. Sevi, and N.J. Shook, "Job Insecurity and Financial Concern During the COVID-19 Pandemic Are Associated With Worse Mental Health", Journal of Occupational and Environmental Medicine 62(9), 2020, pp. 686-691.

[44] Dyer, E., B.J. Swartzlander, and M.R. Gugliucci, "Using virtual reality in medical education to teach empathy", Journal of the Medical Library Association 106(4), 2018, pp. 498-500.

[45] Louie, A.K., J.H. Coverdale, R. Balon, et al., "Enhancing Empathy: a Role for Virtual Reality?", Academic Psychiatry 42(6), 2018, pp. 747-752.

[46] Swartzlander, B., E. Dyer, and M. Gugliucci, "We Are Alfred: Empathy Learned Through A Medical Education Virtual Reality Project", Library Services Faculty Posters, 2017.

[47] Chen, A.M.H., M.E. Kiersma, K.S. Yehle, and K.S. Plake, "Impact of an Aging Simulation Game on Pharmacy Students' Empathy for Older Adults", American Journal of Pharmaceutical Education 79(5), 2015, pp. 1-10.

[48] Taubert, M., L. Webber, T. Hamilton, M. Carr, and M. Harvey, "Virtual reality videos used in undergraduate palliative and oncology medical teaching: results of a pilot study", BMJ supportive \& palliative care 9(3), 2019, pp. 281-285.

[49] Davis, M.H., "A multidimensional approach to individual difference in empathy", JSAS Catalog of Selected Documents in Psychology, (1980), 85.

[50] Alghowinem, S., R. Goecke, M. Wagner, G. Parkerx, and M. Breakspear, "Head Pose and Movement Analysis as an Indicator of Depression", 2013 Humaine Association Conference on Affective Computing and Intelligent Interaction, (2013), 283-288.

[51] Perini, G., M. Cotta Ramusino, E. Sinforiani, S. Bernini, R. Petrachi, and A. Costa, "Cognitive impairment in depression: recent advances and novel treatments", Neuropsychiatric Disease and Treatment 15, 2019, pp. 1249-1258.

[52] Hoffman, K.M., "Social and cognitive affordances of two depression-themed games", Games and Culture, 2019. [53] Kalia, J., Child and Adolescent Depression: Using a CBT Treatment Approach, repository.cityu.edu, 2016. [54] O'Reilly, G., "Pesky gNATs! A CBT Computer Game and App for Young People with Anxiety or Depression.", Early Intervention in Mental Health, 2018.

[55] Desrosiers, A., V. Vine, and D. Klemanski,

"Mindfulness and Emotion Regulation in Depression and Anxiety: Common and Distinct Mechanisms of Action", Depression and anxiety 30, 2013.

[56] Hearn, J.H., and A. Cross, "Mindfulness for pain, depression, anxiety, and quality of life in people with spinal cord injury: a systematic review", BMC Neurology 20(1), 2020 . 
[57] Lopez-Montoyo, A., S. Quero, J. Montero-Marin, et al., "Effectiveness of a brief psychological mindfulnessbased intervention for the treatment of depression in primary care: study protocol for a randomized controlled clinical trial", BMC Psychiatry 19(1), 2019, pp. 301.

[58] Palmer, G., The role of self-compassion in mood repair for people with recurrent depression with and without experience of mindfulness-based cognitive therapy., ore exeter.ac.uk, 2018.

[59] Castilho, P., J. Pinto - Gouveia, and J. Duarte, "Exploring Self-criticism: Confirmatory Factor Analysis of the FSCRS in Clinical and Nonclinical Samples", Clinical Psychology \& Psychotherapy 22(2), 2015, pp. 153-164. [60] Kraus, S., and Æ.S. Sears, "Measuring the

immeasurables: Development and initial validation of the Self-Other Four Immeasurables (SOFI) Scale based on the Buddhist teachings on loving kindness, compassion, joy, and equanimity", Social Indicators Research, 2009, pp. 169-181. 